\title{
Recovery of Sugars from Ionic Liquid Biomass Liquor by Solvent Extraction
}

\author{
Timothy C. R. Brennan • Supratim Datta • \\ Harvey W. Blanch • Blake A. Simmons • \\ Bradley M. Holmes
}

Published online: 2 May 2010

(C) The Author(s) 2010. This article is published with open access at Springerlink.com

\begin{abstract}
The dissolution of biomass into ionic liquids (ILs) has been shown to be a promising alternative biomass pretreatment technology, facilitating faster breakdown of cellulose through the disruption of lignin and the decrystallization of cellulose. Both biological and chemical catalysis have been employed to enhance the conversion of IL-treated biomass polysaccharides into monomeric sugars. However, biomass-dissolving ILs, sugar monomers, and smaller carbohydrate oligomers are all soluble in water. This reduces the overall sugar content in the recovered solid biomass and complicates the recovery and recycle of the IL. Nearcomplete recovery of the IL and the holocellulose is essential for an IL-based pretreatment technology to be economically feasible. To address this, a solvent extraction technique, based on the chemical affinity of boronates such as phenylboronic acid and naphthalene-2-boronic acid for sugars, was applied to the extraction of glucose, xylose, and cellobiose from aqueous mixtures of 1-ethyl-3-methylimidazolium acetate. It was shown that boronate complexes could extract
\end{abstract}

Electronic supplementary material The online version of this article (doi:10.1007/s12155-010-9091-5) contains supplementary material, which is available to authorized users.

T. C. R. Brennan - S. Datta - H. W. Blanch - B. A. Simmons •

B. M. Holmes $(\square)$

Deconstruction Division, Joint BioEnergy Institute,

Emeryville, CA, USA

e-mail: bmholme@sandia.gov

T. C. R. Brennan $\cdot$ H. W. Blanch

Physical Biosciences Division,

Lawrence Berkeley National Laboratory,

Berkeley, CA, USA

S. Datta $\cdot$ B. A. Simmons $\cdot$ B. M. Holmes

Biomass Science and Conversion Technology Department,

Sandia National Laboratories,

Livermore, CA, USA up to $90 \%$ of mono- and disaccharides from aqueous IL solutions, $100 \%$ IL systems, and hydrolysates of corn stover containing IL. The use of boronate complexes shows significant potential as a way to recover sugars at several stages in ionic liquid biomass pretreatment processes, delivering a concentrated solution of fermentable sugars, minimizing toxic byproducts, and facilitating ionic liquid cleanup and recycle.

Keywords Ionic liquid pretreatment - Solvent extraction . Boronic acids · Cellobiose - Glucose Xylose .

Hydrolysate $\cdot$ Ionic liquid recovery and recycling .

1-ethyl-3-methylimidazolium acetate

\section{Introduction}

In recent years, there has been a renewed interest and an increased effort toward the development of biofuels made from lignocellulosic biomass derived from agricultural wastes, forest residues, and dedicated energy crops $[6,11$, 13]. One of the largest limitations facing the overall economic viability of this process is the slow and incomplete hydrolysis of biomass by cellulolytic enzymes into its component sugars $[2,11]$. This recalcitrance necessitates the use of a "pretreatment" step to enhance the accessibility of these enzymes to the carbohydrate complexes present in biomass [11]. Most pretreatments are thermochemical processes that use combinations of high temperatures and pressures, and dilute acids or alkalis, to alter the structure of the biomass and increase surface accessibility. This typically necessitates the use of specialized equipment and high-energy inputs [14, 21, 34].

Ionic liquids (ILs) have received attention as an innovative class of solvents for chemical processing [28, 29]. 


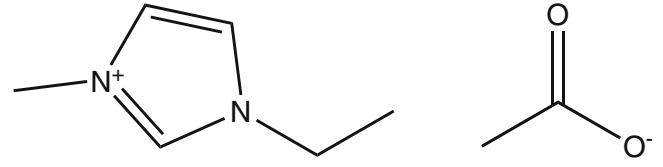

Fig. 1 Molecular schematic of 1-ethyl-3-methylimidazolium acetate $[\mathrm{C} 2 \mathrm{mim}][\mathrm{OAc}]$ used in all extraction and pretreatment experiments

They are known as environmentally friendly solvents primarily due to their low volatility [10] and their potential to be recycled. Recently, ILs have shown great promise for use in the pretreatment of biomass, with several classes of ILs being able to dissolve crystalline cellulose and biomass under relatively mild conditions. The resulting polysaccharides can be readily hydrolyzed using cellulolytic enzymes $[4,16,17]$. The IL 1-ethyl-3-methylimidazolium acetate (Fig. 1), abbreviated as [C2mim][OAc], has been found to be one of the most promising candidates for biomass pretreatment $[27,35]$.

An IL pretreatment process typically involves the dissolution of biomass into the ionic liquid at an elevated temperature with stirring, followed by the addition of an anti-solvent that precipitates a fraction of the biomass from solution (Fig. 2).
This precipitant can be water, ethanol, or a solvent with hydrogen bonding capacity that is added at volumetric ratios of approximately $3: 1$ precipitant/IL. Once the biomass has been precipitated, a solid-liquid separation is performed and the biomass is washed with water to remove any remaining IL prior to an enzymatic hydrolysis process step that yields a monosaccharide product stream suitable for fermentation. Washing is necessary as commercial enzyme mixtures are inhibited by residual IL [31].

The proposed IL deconstruction process contains two streams where the recovery of sugars from aqueous IL solutions would improve the overall process efficiency and help in the recycle of the IL (Fig. 2, stage 1 and stage 2). The most significant of these is the process stream resulting from washing the precipitated biomass (Fig. 2, stage B). The development of cellulases that are active in the presence of ILs [5, 15, 36] would enable the production of monomeric sugars without the need for solid-liquid separation and extensive washing after precipitant addition. This currently results in the dilution of the IL. As it is necessary to remove the precipitant from the wash stream so the IL can be reused, the reduction and possible elimination of washing would help avoid high-energy cost associated
Fig. 2 Process flow depicting pretreatment of biomass utilizing enzymatic catalysis for fermentable sugars and sugar recovery Stages 1 and 2 (The switchgrass image is courtesy of the Samuel Roberts Noble Foundation, Ardmore, Oklahoma)

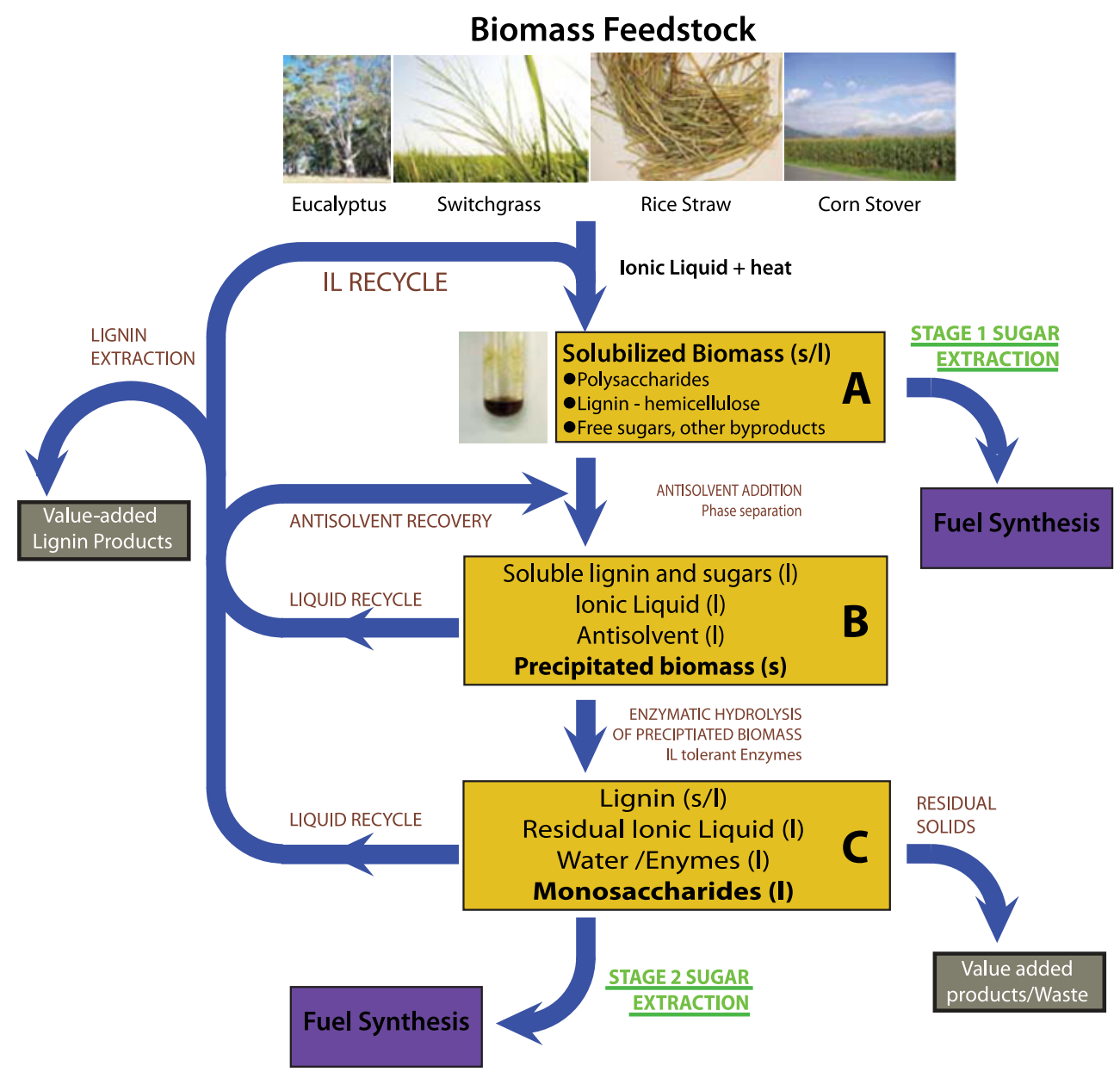




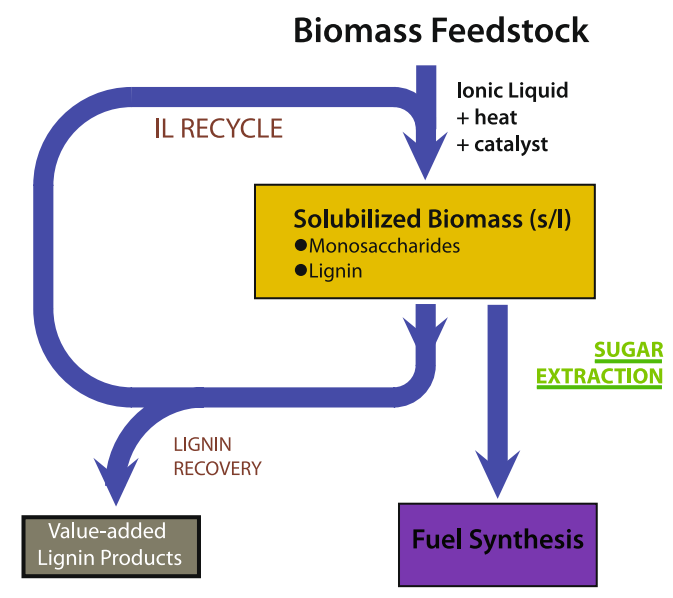

Fig. 3 Process flow depicting solubilization of biomass followed by heterogeneous or homogeneous catalysis for the breakdown of sugars into monomers

with distillation to recover the IL. Families of cellulases that are active at IL concentrations of up to $30 \%(v / v)$ have been recently reported [22, 31, 33], with some hyperthermophilic IL-tolerant enzymes exhibiting between 50\% and $90 \%$ of their activity in the presence of $15 \%$ [C2mim] [OAc] [5].

An alternative IL-based process, using chemical catalysis rather than enzymatic hydrolysis to break down cellulose, is a second avenue through which ionic liquids could be used to produce monomeric sugars (Fig. 3). Homogeneous catalysis, utilizing low concentrations $(\sim 5 \%)$ of mineral acids such as $\mathrm{HCl}$ and $\mathrm{H}_{2} \mathrm{SO}_{4}$ in 1-butyl-3-methylimidazolium chloride $([\mathrm{C} 4 \mathrm{mim}] \mathrm{Cl})$ has been shown to effectively hydrolyze cellulose into its individual oligosaccharide components, with yields of up to $80 \%$ of the total reduced sugars $[18,19]$. Sulfonate resins have also been used to catalyze the selective depolymerization of cellulose dissolved in $[\mathrm{C} 4 \mathrm{mim}] \mathrm{Cl}$, producing lower degree of polymerization cellooligomers [23]. These chemical processes provide promising options for the hydrolysis and breakdown of lignocellulosic material into monosaccharides using the biomass-solvating capacity of ionic liquids.

Development of both IL-tolerant cellulases and chemical catalysis routes for the breakdown of biomass in ionic liquids would help increase the efficiency of the conversion of biomass into monosaccharides. However, both these processes rely on the removal of sugars from aqueous IL solution or from IL biomass liquor. Liquid-liquid extraction of sugars into organic phases has been used to recover up to $98 \%$ of sugars from aqueous solutions [30] and wood hydrolysates [12]. Through the formation of a complex with lipophilic-boronic acids, it is possible for sugars to pass into a water-immiscible organic phase consisting of a lipophilic quaternary alkyl amine salt (Aliquat $336^{\mathrm{TM}}, \mathrm{Q}+$ in Scheme 2) and hexane $[1,12,20,30]$. The mechanism of this complexation relies on the ionization of the boronic acid with $\mathrm{OH}^{-}$under basic conditions, resulting in the formation of a tetrahedral anion at the interface of the aqueous and organic phases (Scheme 1). The tetrahedral anion forms a complex with the cis-diols of pentose and hexose sugars (Scheme 2). For naphthalene-2-boronic acid (N2B), the most efficient removal of sugars occurs at $\mathrm{pH}$ levels between 11 and 12 , above its $\mathrm{p} K_{\mathrm{a}}$ of $\sim 9$. The negatively charged complex is then stabilized in the organic phase by the quaternary alkyl amine cation. The complexation reaction is reversible under acidic conditions and the sugar is recovered from the organic phase by stripping with a dilute acidic solution (Scheme 3). Figure 4 illustrates the overall process. In this study, the use of boronic acids to extract glucose, xylose, and cellobiose from aqueous IL solutions and from ionic liquidonly systems was investigated to determine the efficiency of sugar recovery in the presence of IL. Ionic liquid loss, and degradation was also investigated.

\section{Materials and Experimental Methods}

\section{Ionic Liquid/Sugar Solutions}

Ionic liquid/water solutions were prepared using specified volumes of 1-ethyl-3-methylimidazolium acetate (SigmaAldrich, BASF quality $\geq 90 \%$ ) and $0.15 \mathrm{M} \mathrm{NaHCO}_{3}$ buffer, pH 11 (Mallinckrodt Chemicals, 99.7-100.3\%). The $0.15 \mathrm{M}$ $\mathrm{NaHCO}_{3}$ buffer was prepared by the dissolution of $1.26 \mathrm{~g}$ $\mathrm{NaHCO}_{3}$ buffer in $80 \mathrm{ml}$ of water and adjustment of the $\mathrm{pH}$ to 11 with $\mathrm{NaOH}$ before adjusting the volume to $100 \mathrm{ml}$. The $\mathrm{pH}$ was measured using an ion-sensitive field effect transistor $\mathrm{pH}$ probe (IQ Scientific Instruments Inc., model IQ240). Experiments were conducted using 0\% to $100 \%(v / v)$ $[\mathrm{C} 2 \mathrm{mim}][\mathrm{OAc}] /$ buffer containing $10 \mathrm{mM}$ synthetic anhydrous D-glucose, xylose, or cellobiose (Sigma-Aldrich,
Scheme 1 Formation of the N2B tetrahedral ion under basic conditions [1]

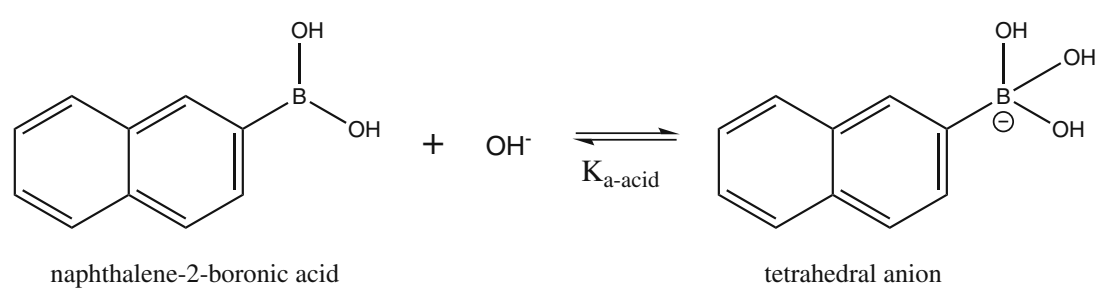




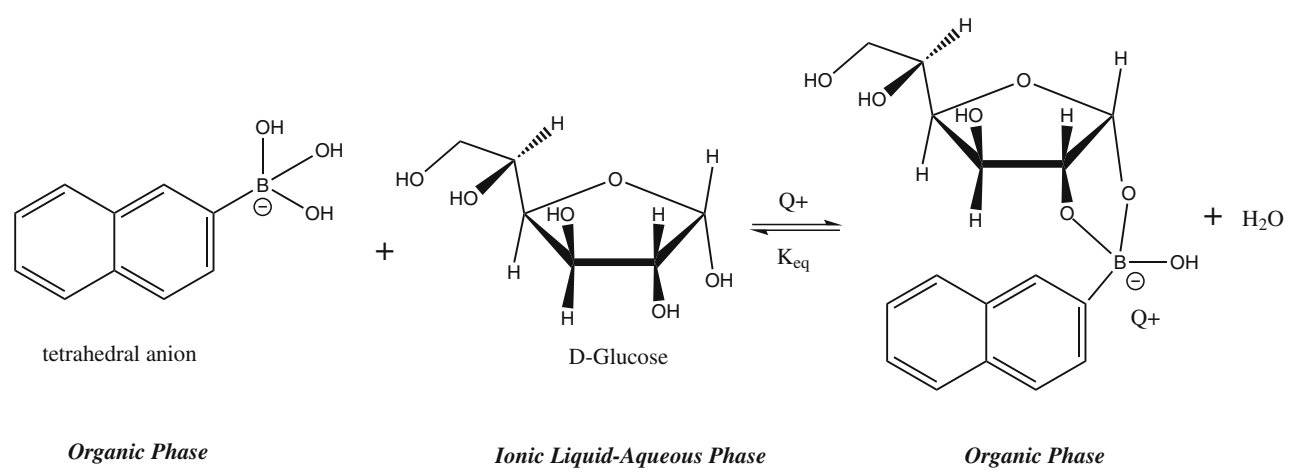

Scheme 2 Tetrahedral boronate anion forms a complex with the cis-diol moiety of the carbohydrate. D-Glucose in the $\alpha$-Furanose form is shown [1]. The $\mathrm{Q}+$ is the quarternary amine Aliquat 336

$>98 \%$ ) in a total volume of $5 \mathrm{ml}$. Carbohydrate structures are shown in Fig. 5. For 100\% IL systems, the correct mass of dry sugars was added. In addition to the $100 \% \mathrm{IL} /$ sugar solution, the $100 \% \mathrm{IL} /$ sugar solution was spiked with $5 \mu 1$ of $10 \mathrm{~N} \mathrm{NaOH}$ (VWR cat. no. VW3247-1) to test if additional hydroxide improved sugar extraction. The specified concentration of water in $[\mathrm{C} 2 \mathrm{mim}][\mathrm{OAc}]$ as received from the supplier was $<0.2 \%$, and so the addition of $5 \mu \mathrm{l}$ of $\mathrm{NaOH}$ $(0.1 \%)$ was treated as negligible. For all experimental trials in this study, the initial $\mathrm{pH}$ of the $\mathrm{IL} /$ water/sugar solutions was measured and buffered to $\mathrm{pH} 11-12$.

\section{Organic Phase}

The organic phase consisted of $150 \mathrm{mM}$ Aliquat $336^{\mathrm{TM}}$ (Sigma-Aldrich, $\rho / \rho_{\mathrm{w}}=0.884 \mathrm{~g} / \mathrm{cm}^{3}$ ) and $70 \mathrm{mM}$ boronic acid. Napthelene-2-boronic acid (Frontier Scientific, 97\%, batch 14973) or phenylborinic acid (Fluka Analytical, $\geq 97 \%)$ were dissolved in a 85:15 (v/v) solution of $n$-hexane and 1-octanol.

\section{Stripping Solution}

An aqueous solution of $0.5 \mathrm{M}$ hydrochloric acid was used to strip the sugars from the loaded organic solution.

\section{Quantitation of Sugars}

Sugar concentrations were measured using HPAEC with pulsed amperometric detection on a Dionex DX600 equipped with a Dionex Carbopac PA-20 analytical column $(3 \times 150 \mathrm{~mm})$ and a Carbopac PA-20 guard column (3× $30 \mathrm{~mm}$; Dionex, Sunnyvale, CA, USA). Eluent flow rate was $0.4 \mathrm{ml} / \mathrm{min}$ and the temperature was $30^{\circ} \mathrm{C}$. A gradient consisting of a 12-min elution with $14 \mathrm{mM} \mathrm{NaOH}$ followed by a 5 -min ramp to $450 \mathrm{mM} \mathrm{NaOH}$ for $20 \mathrm{~min}$, returning to the original $\mathrm{NaOH}$ concentration of $14 \mathrm{mM}$ for 10 min prior to the next injection, was employed. External standards covering the range between 6.25 and $125 \mu \mathrm{M}$ glucose, xylose, and cellobiose were used to generate calibration curves from which concentrations were determined. Figure 6 displays a typical chromatogram used to determine carbohydrate concentrations.

Preparation of Hydrolysate Solutions

\section{Pretreatment}

A total of $300 \mathrm{mg}$ of corn stover (4.8\% moisture content) was mixed with $9.7 \mathrm{~g}$ of [C2mim][OAc] (as received, $<0.2 \%$ moisture specified) in a $30-\mathrm{ml}$ test tube. The con-

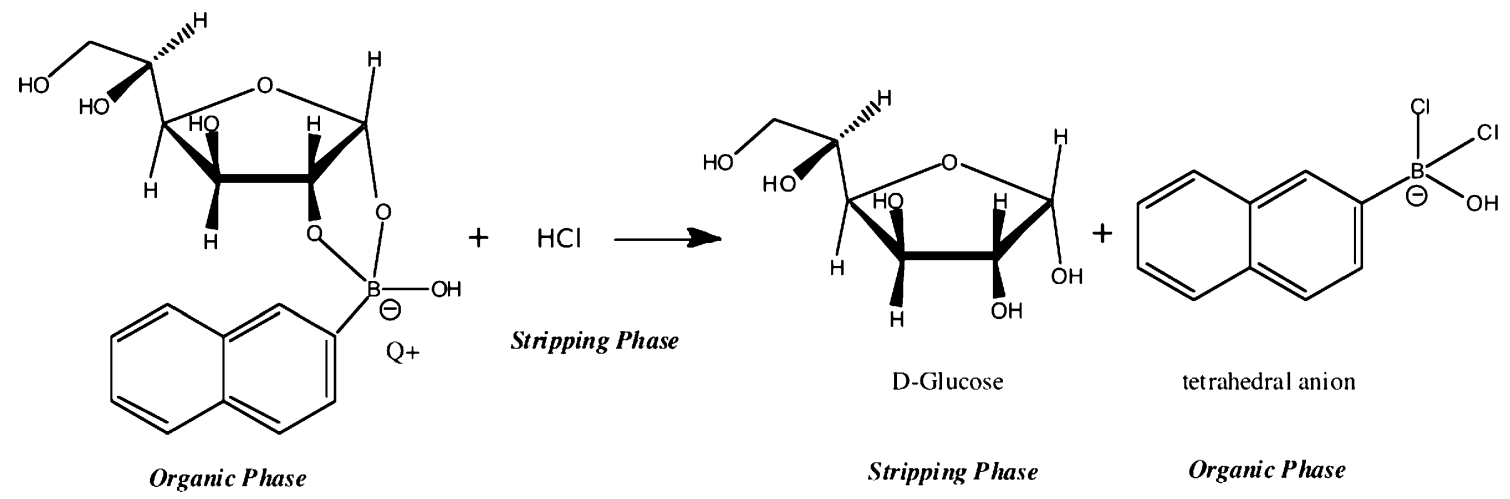

Scheme 3 Possible mechanism for the stripping of sugars from the tetrahedral boronate complex using $\mathrm{HCl}$ [1] 
tents were stirred with magnetic stirring in an oil bath at $120^{\circ} \mathrm{C}$. After $3 \mathrm{~h}, 20 \mathrm{ml}$ of hot water was slowly added to the mixture with vortexing to precipitate the dissolved biomass. The resulting slurry was washed with $4 \times 40 \mathrm{ml}$ of water to remove the ionic liquid and resuspended in $50 \mathrm{mM}$ sodium acetate buffer, $\mathrm{pH} 4.8$.

\section{Enzymatic Hydrolysis}

A cellulase cocktail consisting of a Novozymes cellulase complex, NS50013 (70 FPU/g), and B-glucosidase, NS50010 $(250 \mathrm{CBU} / \mathrm{g})$, was prepared according to the manufacturers instructions. An enzyme loading of 5\% NS50013 and 0.5\% NS50010 (wt enzyme/wt glucan) was added to the recovered biomass, and shaken at $250 \mathrm{rpm}$ for 72 hours at $50^{\circ} \mathrm{C}$. The hydrolysate was then filter-sterilized and stored at $4^{\circ} \mathrm{C}$ until used. The concentration of glucose was $200 \mathrm{mM}$.

\section{Preparation of IL/hydrolysate Solutions}

Solutions containing 6.8 and $20.4 \mathrm{mM}$ glucose were prepared using the hydrolysate and spiked with $5 \%, 10 \%$, and $15 \%(v / v)[\mathrm{C} 2 \mathrm{mim}][\mathrm{OAc}]$ with the volume made up with $150 \mathrm{mM}$ of the $\mathrm{NaHCO}_{3}$ buffer, $\mathrm{pH} 11$.

\section{Extraction and Stripping of Sugars}

The extraction of sugars was adapted from the method of Griffin and Shu [12]. Extraction experiments were conducted separately for each sugar (glucose, xylose, and
Fig. 4 Extraction flow sheet and corresponding substances in each phase

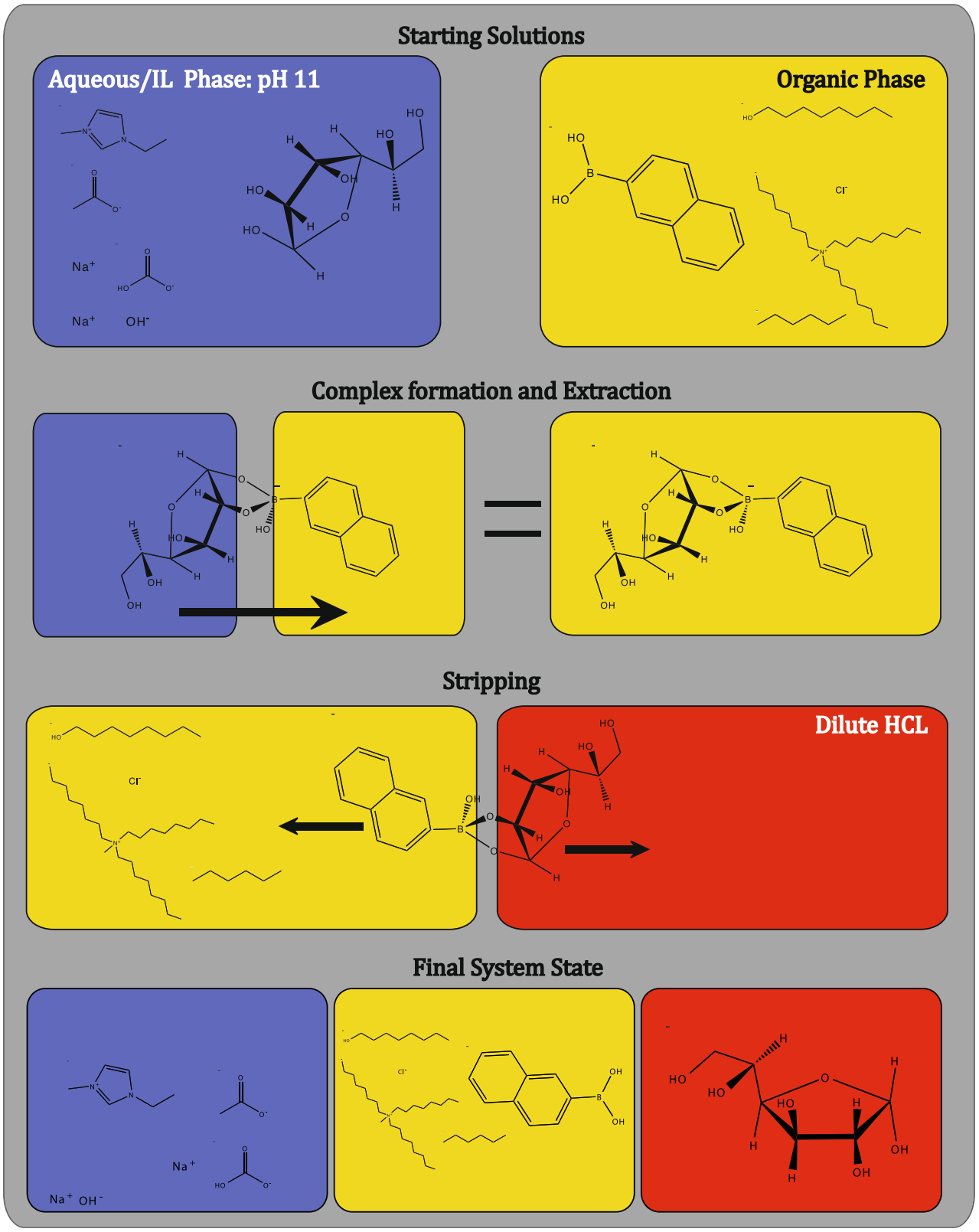




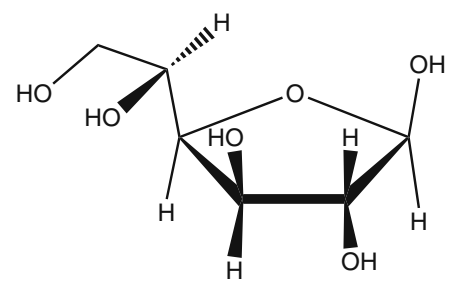

D-Glucose

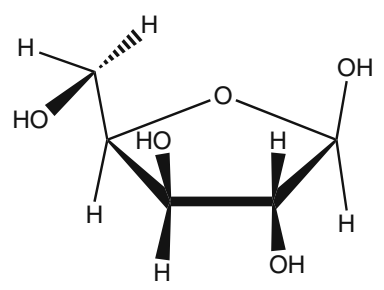

D-Xylose<smiles>OC[C@H]1O[C@H](O)[C@H](O)[C@@H](O)[C@H]1C[C@H]1O[C@H](CO)[C@H](O)[C@H](O)[C@H]1O</smiles>

Cellobiose

Fig. 5 Three carbohydrates of interest in this study: D-glucose, D-xylose, and cellobiose

cellobiose) and for the IL/hydrolysate solution. Equal volumes of IL/water sugar solutions $(0-100 \% \mathrm{IL})$ and organic phase were vigorously mixed at $1,400 \mathrm{rpm}, 25^{\circ} \mathrm{C}$, for 2 hours (Eppendorf Thermomixer). Tubes were then transferred to a centrifuge (Eppendorf centrifuge 5434) and spun at $13,000 \mathrm{rpm}$ for $5 \mathrm{~min}$ to separate the two phases. Samples of the IL/water phase were then analyzed using highperformance anion exchange chromatography (HPAEC) to determine the quantity of sugars transferred into the organic phase. Positive controls of known initial starting sugar solutions $(10 \mathrm{mM})$ were used to validate the experimental protocol, with $<5 \%$ variation observed. Stripping sugar experiments were conducted by taking the loaded organic phase and vigorously mixing it with an equal volume of stripping solution $(0.5 \mathrm{M} \mathrm{HCl}$, mixing for $30 \mathrm{~min}$ and spinning down in centrifuge for $5 \mathrm{~min}, 13,000 \mathrm{rpm}$ ). Samples of the aqueous stripping solution were analyzed using HPAEC to determine the quantity of sugars recovered from the loaded organic phase. All experiments were performed at $25^{\circ} \mathrm{C}$.
All trials were conducted in triplicate. The percent extracted was defined as the percentage of sugar, on a molar basis, initially present in the IL or IL/water phase that is transferred into the organic phase:

$\%$ Extracted $=\frac{\left([\text { Sugar }]_{\text {initial }}-[\text { Sugar }]_{\text {final }}\right)}{[\text { Sugar }]_{\text {initial }}} \times 100$

\section{Results and Discussion}

\section{Extraction of Sugars}

The results of all extraction trials are presented in Figs. 7, 8, 9, 10, 11, 12, 13, and 14. Error bars represent one standard deviation above and below the mean. For all experiments in this study, the $\mathrm{pH}$ of the IL/water/sugar solution before and after extraction did not change. For both N2B and phenyl-
Fig. 6 Chromatogram displaying the change in glucose concentration before and after extraction from $50 \% \mathrm{IL} /$ water. The larger (Glc-12.05 $\mathrm{min}$ ) is the IL/buffer/sugar sample before extraction. The smaller peak is the sample after extraction

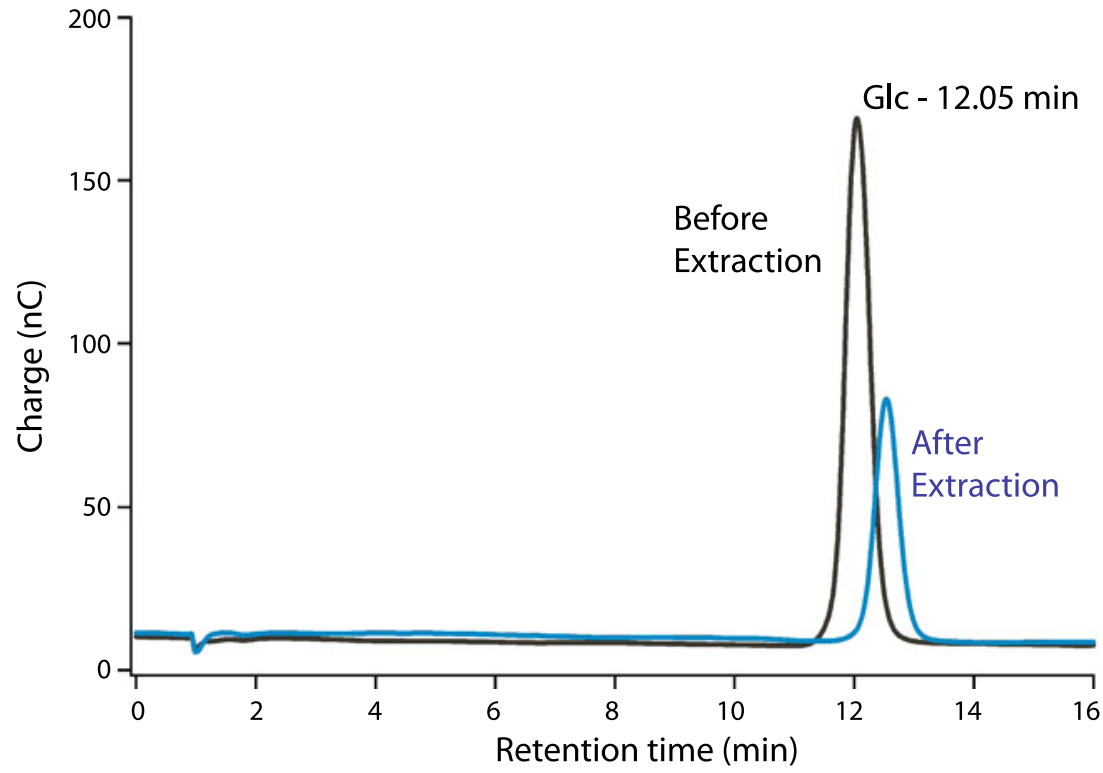


PBA Extraction of Glucose and Xylose

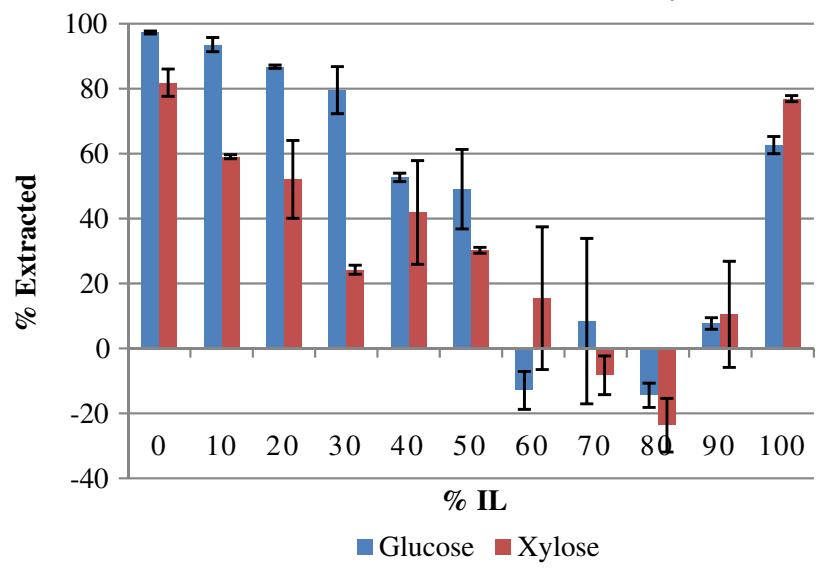

Fig. 7 Phenylboronic acid $(P B A)$ extraction of glucose and xylose from aqueous $[\mathrm{C} 2 \mathrm{mim}][\mathrm{OAc}]$ solutions. PBA concentration was $70 \mathrm{mM}$ in organic phase and initial sugar concentration in the IL/ water phase before extraction was $10 \mathrm{mM}$ and at $\mathrm{pH} 11$. All extraction trials in this study were at ambient temperature $25^{\circ} \mathrm{C}$

boronic acid (PBA), a higher percentage in terms of extraction and recovery of glucose than xylose for IL/water solutions from $0 \%$ to $50 \%$ IL was observed (Figs. 7 and 8). Of the two boronic acids, N2B had a higher affinity for xylose than PBA (Fig. 10). For glucose, a clear trend was inconclusive in the region from $0 \%$ to $30 \% \mathrm{IL}$, but $\mathrm{N} 2 \mathrm{~B}$ had greater extraction percentages than $\mathrm{PBA}$ in $40 \%$ and $50 \%$ IL (Fig. 9). Negligible amounts of cellobiose were extracted by $\mathrm{PBA}$ or $\mathrm{N} 2 \mathrm{~B}$ in the $0 \%$ to $50 \%$ IL region (Table 1).

For IL/water solutions of $60-90 \%$ IL, small amounts of white precipitate were observed. While not tested, this is most likely sodium bicarbonate precipitating at high salt

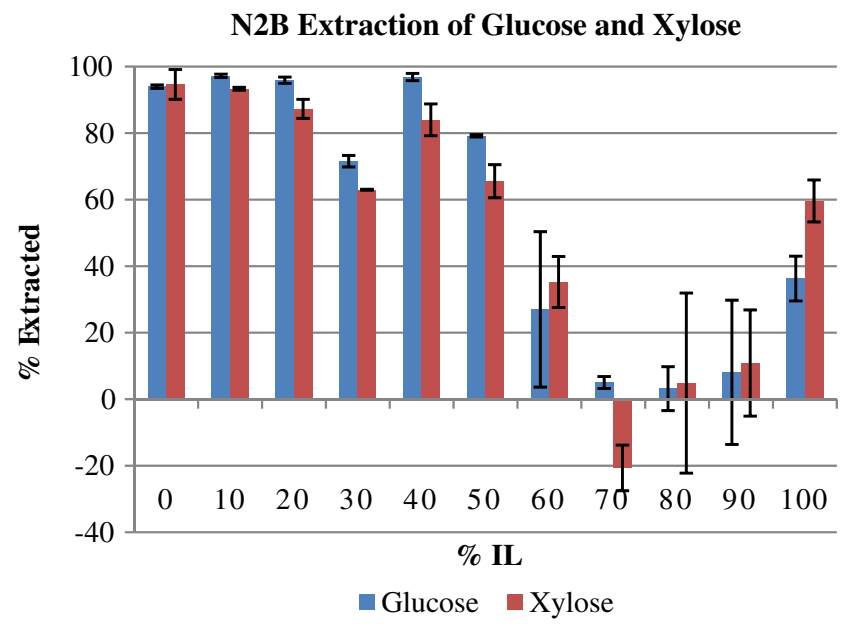

Fig. 8 Napthalene-2-boronic acid extraction of glucose and xylose from aqueous $[\mathrm{C} 2 \mathrm{mim}][\mathrm{OAc}]$ solutions. N2B concentration was $70 \mathrm{mM}$ in organic phase and initial sugar concentration in the IL/ water phase before extraction was $10 \mathrm{mM}$ and at $\mathrm{pH} 11$
Comparison of glucose extraction efficiency of N2B vs. PBA organic phases

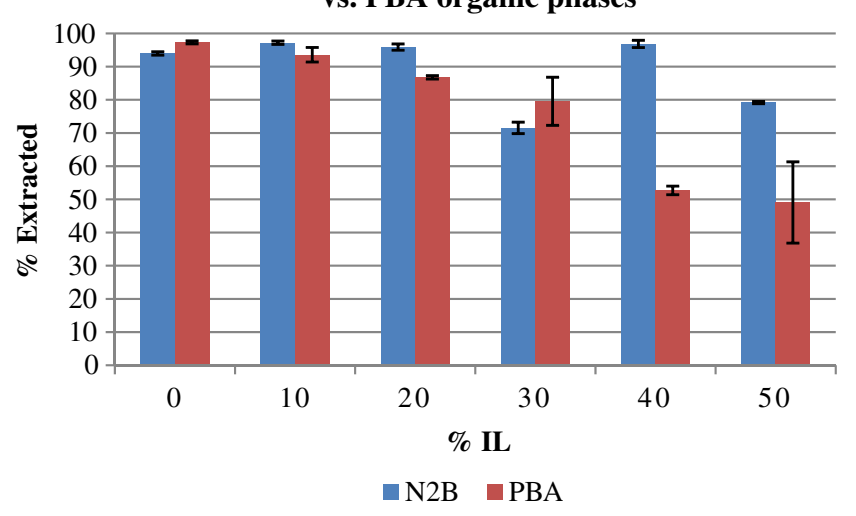

Fig. 9 Percent glucose extraction comparing napthalene-2-boronic acid $(N 2 B)$ and phenylboronic acid $(P B A)$. Extractant concentrations were $70 \mathrm{mM}$ in organic phase and initial sugar concentration in the IL/ water phase before extraction was $10 \mathrm{mM}$ and at $\mathrm{pH} 11$

concentrations. The extraction of the sugars using both $\mathrm{N} 2 \mathrm{~B}$ and PBA at these ionic liquid concentrations became highly variable, with negligible amounts of glucose, xylose, and cellobiose extracted (Figs. 7 and 8 and Table 1). Evaporation was considered and rejected as a potential source of this variability through the use of positive controls using known sugar concentrations $(10 \mathrm{mM})$. Under these high salt loadings, it is unknown what the actual activity of $\left[\mathrm{OH}^{-}\right]$ions are and how they influence the association constant $\left(K_{\mathrm{a} \text {-acid }}\right)$ of the tetrahedral boronate anion (Scheme 1) and the association constant of the tetrahedral anion and the sugar diols $\left(K_{\text {eq }}\right.$ in Scheme 2). Literature suggests that upon the formation of boronate ester, the $\mathrm{p} K_{\mathrm{a}}$ decreases compared to the boronic acid itself, resulting in an overall decrease in the $\mathrm{pH}$ of the solution

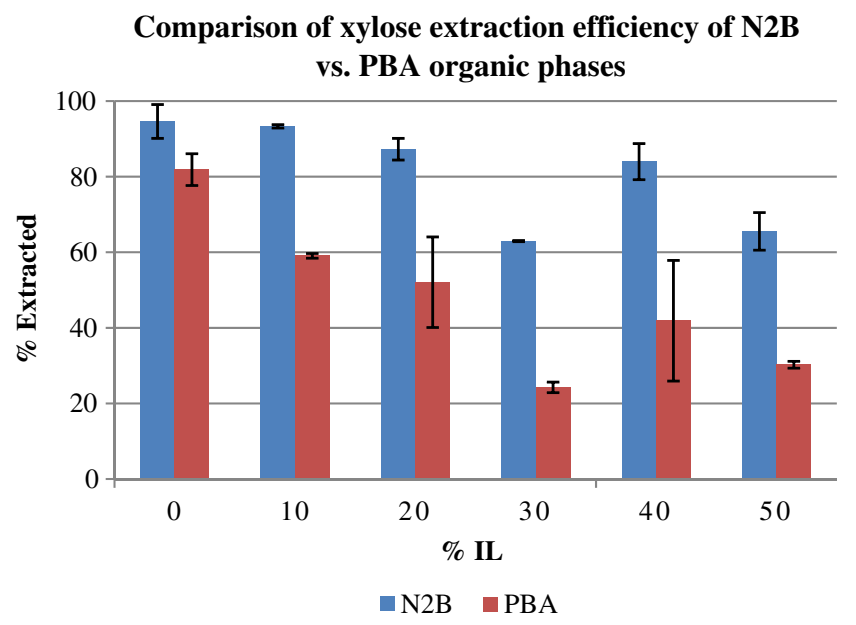

Fig. 10 Percent xylose extraction comparing napthalene-2-boronic and phenylboronic acids. Extractant concentrations were $70 \mathrm{mM}$ in organic phase and initial sugar concentration in the IL/water phase before extraction was $10 \mathrm{mM}$ and at $\mathrm{pH} 11$ 
Extraction of sugars from $100 \%$ [C2Mim][OAc] using PBA organic phase

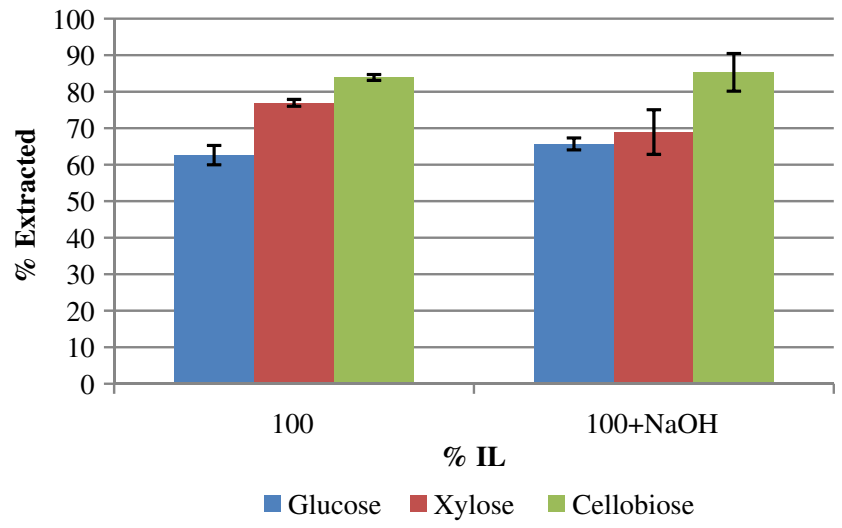

Fig. 11 Phenylboronic acid extraction of glucose, xylose, and cellobiose in $100 \%$ IL and $100 \%$ IL spiked with $\mathrm{NaOH}$. The latter solution was spiked with $\mathrm{NaOH}$ by adding $5 \mu \mathrm{l} 10 \mathrm{~N} \mathrm{NaOH}$ to the $5-\mathrm{ml}$ volume of the IL/sugar mixture before extraction. The specified concentration of water in $[\mathrm{C} 2 \mathrm{mim}][\mathrm{OAc}]$ as received from the supplier was $<0.2 \%$. The addition of $5 \mu \mathrm{l}$ of $\mathrm{NaOH}$ represents approximately $0.1 \%$ increase in water content and is treated as negligible. PBA concentration was $70 \mathrm{mM}$ in organic phase and initial sugar concentration in the IL phase before extraction was $10 \mathrm{mM}$

[32]. In our study, the $\mathrm{pH}$ was not observed to decrease, and it is unknown to what extent the ions in $[\mathrm{C} 2 \mathrm{mim}][\mathrm{OAc}]$ are interacting with $\left[\mathrm{H}^{+}\right]$or $\left[\mathrm{OH}^{-}\right]$in solution. These factors may be the source of the wide variation in the extent of extraction. Further investigation is needed to fully understand these results.

In aqueous solutions, it has been reported that while the binding constants of boronic acid-carbohydrate complexes are buffer-independent $[3,26]$, the stability of the boronate

\section{Extraction of sugars from 100\% [C2Mim][OAc] using N2B organic phase}

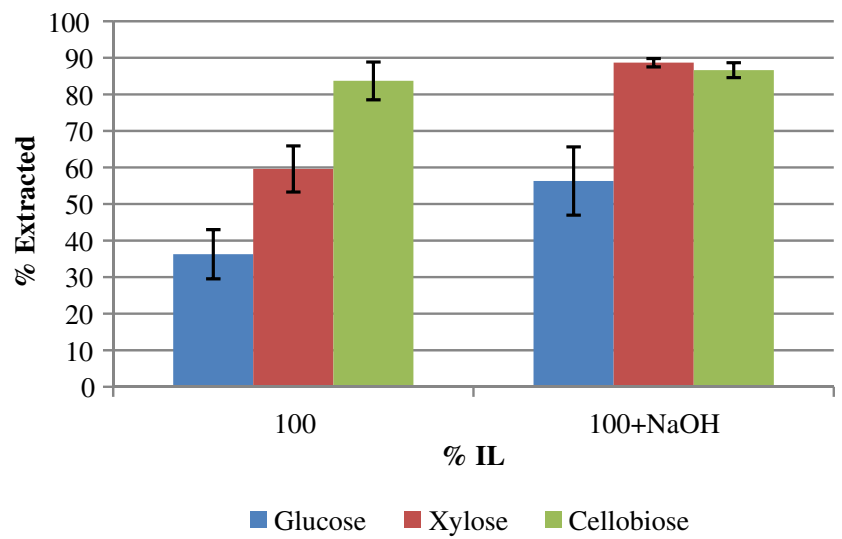

Fig. 12 Extraction efficiency of glucose, xylose, and cellobiose in $100 \%[\mathrm{C} 2 \mathrm{Mim}][\mathrm{OAc}]$ and $100 \%$ [C2Mim] [OAc] spiked with $5 \mu \mathrm{l}$ $10 \mathrm{~N} \mathrm{NaOH}$ to the 5-ml volume of the IL/sugar mixture before extraction. Napthalene-2-boronic acid concentration was $70 \mathrm{mM}$ in the organic phase and initial sugar concentration in the IL phase before extraction was $10 \mathrm{mM}$
Extraction of Glucose from Corn Stover Hydrolysate

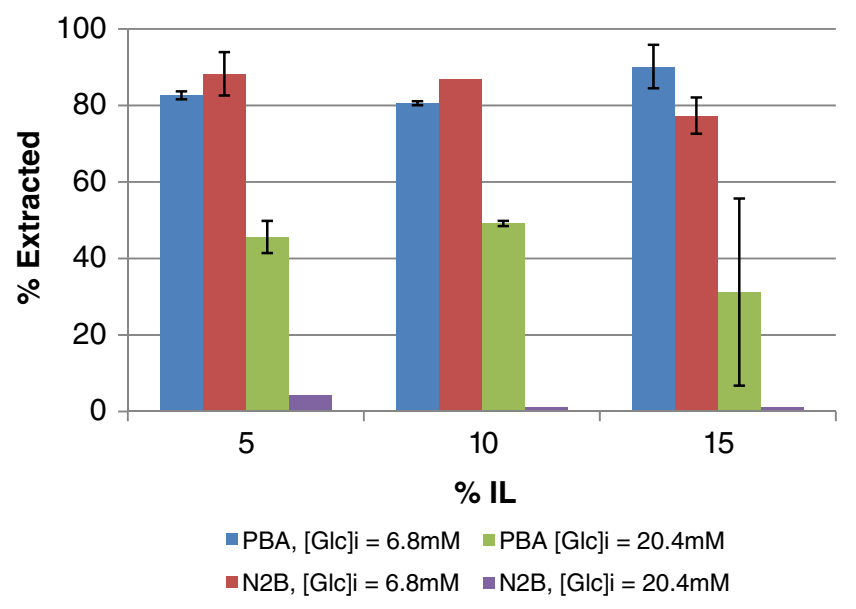

Fig. 13 Percentage extraction of glucose from pretreated corn stover hydrolysate in the presence of [C2mim][OAc]. Two different $(6.8$ and $20.4 \mathrm{mM}$ ) initial hydrolysate/glucose concentrations were tested. The organic phase consisted of $70 \mathrm{mM}$ boronic acid and $150 \mathrm{mM}$ Aliquat 336 in hexane/octanol (85:15). IL/hydrolysate solutions were at $\mathrm{pH} 11$

ester is $\mathrm{pH}-$ and solvent-dependent $[24,32]$. Springsteen and Wang [26] reported association constants $\left(K_{\mathrm{eq}}\right)$ in aqueous systems for D-glucose and D-xylose to be 4.6 and $14 \mathrm{M}^{-1}$ respectively, at $\mathrm{pH}$ 7.4. $K_{\text {eq }}$ is a function of the two equilibrium constants ( $K_{\text {eq-tet }}$ and $K_{\text {eq-trig }}$ ) for the tetrahedral and trigonal forms of the boronic acid with the sugar diols. These authors also reported that $K_{\text {eq }}$ increased with increasing $\mathrm{pH}$ for the D-glucose complex with phosphate buffer. At $\mathrm{pH}$ values of 7.0, 7.4, 8.0, and 8.5, the $K_{\text {eq }}$ values were $2.0,4.6,7.2$, and $11 \mathrm{M}^{-1}$, respectively, and the optimal binding $\mathrm{pH}$ for the boronate ester was not always above the $\mathrm{p} K_{\mathrm{a}}$ of the boronate species (the authors reported

\section{Recovery of Glucose from Corn Stover Hydrolysates}

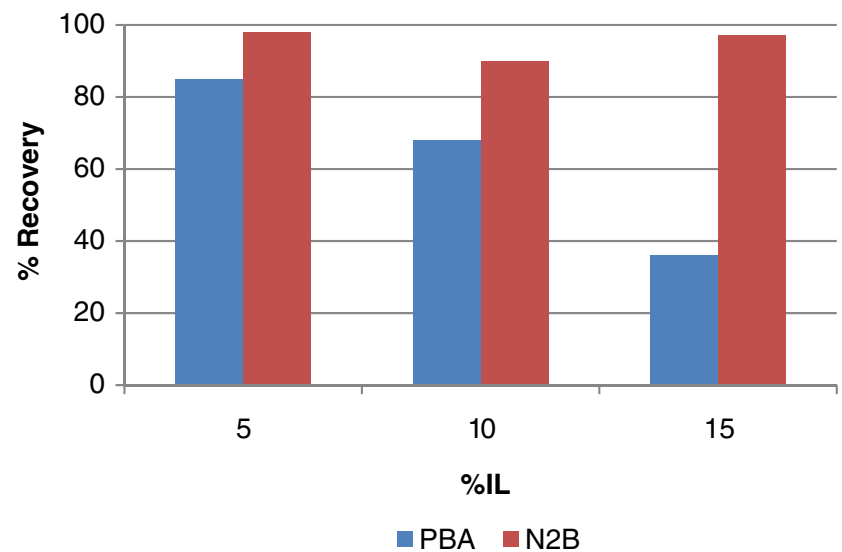

Fig. 14 Percentage recovery of glucose stripped from loaded organic phase (6.8 mM glucose original hydrolysate concentration) using dilute $\mathrm{HCl}$. The organic phase, containing $70 \mathrm{mM}$ boronic acid, was contacted with equal volumes of stripping solution containing $0.5 \mathrm{M} \mathrm{HCl}$ 
that the binding constants were at a maximum around $\mathrm{pH} 7$ ) [26]. $K_{\text {eq }}$ values were not reported for $\mathrm{pH}$ above 9. In our high IL concentration systems, how the [C2mim][OAc] species affect the binding affinity and equilibrium constants between the boronic acids and carbohydrates was undetermined and is the subject of further study.

The results obtained in 100\% IL-sugar solutions were unexpected. In both $100 \%[\mathrm{C} 2 \mathrm{mim}][\mathrm{OAc}]$ and spiked (addition of $\mathrm{NaOH}$ ) $100 \%$ [C2mim] [OAc], not only were all three sugars extracted to a significant amount $(>60 \%$ extracted in PBA), cellobiose was also extracted to a greater extent than either xylose or glucose (over $80 \%$ in Figs. 11 and 12). According to Scheme 1, hydroxide ions are required for the conversion of boronates to the tetrahedral anion formation. However, in $100 \%$ IL solutions, no buffer was present to allow this transformation. Hence, the boronic acids alone, without conversion to the tetrahedral form, possibly formed a stable species with the sugars in the organic phase. In addition, $100 \%$ [C2mim][OAc] solutions that were spiked with $\mathrm{NaOH}$ showed higher degrees of extraction when using N2B (Fig. 12). While this may imply that the N2B is forming a tetrahedral anion with the addition of $\mathrm{OH}-$ to enhance the extraction of sugars, the same trend was not observed when extracting with PBA (Fig. 11). A more in-depth investigation of the structure of the boronic acid-sugar complex under this condition is required before conclusions can be drawn about the mechanism of extraction in this $100 \%$ IL case.

Table 1 Extraction data for each sugar at varying amounts of ionic liquid

\begin{tabular}{|c|c|c|c|c|c|c|}
\hline \multirow[t]{2}{*}{$\% \mathrm{IL}$} & \multicolumn{3}{|c|}{ Average \% Extr } & \multicolumn{3}{|l|}{ SD } \\
\hline & Glucose-N2B & Xylose-N2B & Cellobiose-N2B & Glucose-N2B & Xylose-N2B & Cellobiose-N2B \\
\hline 0 & 94 & 95 & 0 & 1 & 4 & 3 \\
\hline 10 & 97 & 93 & 0 & 1 & 0 & 28 \\
\hline 20 & 96 & 87 & -1 & 1 & 3 & 0 \\
\hline 30 & 72 & 63 & 12 & 2 & 0 & 26 \\
\hline 40 & 97 & 84 & -8 & 1 & 5 & 2 \\
\hline 50 & 79 & 66 & 9 & 0 & 5 & 26 \\
\hline 60 & 27 & 35 & -10 & 23 & 8 & 3 \\
\hline 70 & 5 & -21 & 9 & 2 & 7 & 26 \\
\hline 80 & 3 & 5 & -23 & 7 & 27 & 2 \\
\hline 90 & 8 & 11 & -17 & 22 & 16 & 22 \\
\hline 100 & 36 & 60 & 84 & 7 & 6 & 5 \\
\hline \multirow[t]{2}{*}{$100+\mathrm{NaOH}$} & 56 & 89 & 87 & 9 & 1 & 2 \\
\hline & Glucose-PBA & Xylose-PBA & Cellobiose-PBA & Glucose-PBA & Xylose-PBA & Cellobiose-PBA \\
\hline 0 & 97 & 82 & 30 & 0 & 4 & 23 \\
\hline 10 & 94 & 59 & 11 & 2 & 1 & 4 \\
\hline 20 & 87 & 52 & 17 & 1 & 12 & 33 \\
\hline 30 & 80 & 24 & 20 & 7 & 1 & 34 \\
\hline 40 & 53 & 42 & 9 & 1 & 16 & 24 \\
\hline 50 & 49 & 30 & -12 & 12 & 1 & 13 \\
\hline 60 & -13 & 15 & -3 & 6 & 22 & 16 \\
\hline 70 & 8 & -8 & -29 & 25 & 6 & 3 \\
\hline 80 & -14 & -24 & -33 & 4 & 8 & 29 \\
\hline 90 & 8 & 11 & 1 & 2 & 16 & 22 \\
\hline 100 & 63 & 77 & 84 & 3 & 1 & 1 \\
\hline $100+\mathrm{NaOH}$ & 66 & 69 & 85 & 2 & 6 & 5 \\
\hline
\end{tabular}

The average value was taken from triplicate samples and standard deviation (SD) is shown. Negative extraction values correspond to greater final sugar content than initial, which could have been due to experimental error or issues addressed in the results section. Positive controls of known initial starting solutions were conducted and validated. Initial sugar concentrations were $10 \mathrm{mM}$ prior to extraction, and the organic phase contained $70 \mathrm{mM}$ boronic acid. Solutions were at $\mathrm{pH} 11-12$ and ambient temperature 
The possible degradation of the ionic liquid during the experiment was investigated, as it has been reported that the under basic conditions the acid-labile hydrogen on the $\mathrm{C} 2$ position of the imidazole is lost, resulting in the formation of N-heterocyclic carbenes. ${ }^{1}$ HMR and FTIR showed that no carbene product was formed under the extraction conditions (see Electronic supplementary material, Figs. S1-S4).

\section{Extraction of Glucose from Pretreated Corn Stover}

For both N2B and PBA systems, extraction of $80-90 \%$ of the original glucose contained in the hydrolysate was achieved (Fig. 13). Within experimental error, there was no impact on the extraction efficiency with increasing concentration of [C2mim][OAc] $(5-15 \%, v / v)$. A more concentrated hydrolysate solution $(20.4 \mathrm{mM}$ glucose vs. $6.8 \mathrm{mM}$ glucose) was extracted in parallel to test the capacity of the two extraction systems. The concentration of boronic acids was kept constant at $70 \mathrm{mM}$. As seen in Fig. 13, the percentage extraction may be dependent on the boronic acid concentration in the organic phase, with $\sim 50 \%$ of the original $20.4 \mathrm{mM}$ glucose in the hydrolysate being extracted, compared to the $\sim 80 \%$ of the $6.8 \mathrm{mM}$ glucose. While the maximum theoretical loading of sugars in the organic phase is unknown, this reduction in extraction efficiency implies that the $70 \mathrm{mM}$ boronic acid system may be approaching its theoretical limit.

\section{Recovery of Glucose from Corn Stover Hydrolysates}

The recovery of glucose from corn stover hydrolysate samples reached up to $97 \%$. Samples extracted with N2B showed the highest percent recovery compared to samples treated with PBA (where the percentage recovery is defined in Eq. 2 as the percentage of sugars in the organic phase that is transferred to the stripped solution). Samples treated with PBA had a decrease in percentage recovery with increasing IL content:

$\%$ Recovery $=\frac{\left([\text { Sugar }]_{\text {organic phase }}-[\text { Sugar }]_{\text {stripped phase }}\right)}{[\text { Sugar }]_{\text {organic phase }}} \times 100$

Alternatively, samples extracted with N2B recovered 90 $97 \%$ of glucose from the loaded organic phase regardless of IL content (Fig. 14). Therefore, this stripping technique can provide a process to deliver fermentable sugars extracted from pretreated hydrolysate solutions efficiently.

\section{Conclusion}

The extraction of mono- and disaccharides in ionic liquidbased systems using boronic acids has been shown to be an effective technology to provide fermentable sugars from pretreated lignocellulosic biomass. This boronic acid extraction technology has not been previously employed with ionic liquid systems and offers the possibility of efficiently recovering C5 and C6 sugars from ionic liquids. The complete extraction of cellobiose in $100 \% \mathrm{IL}$ is also encouraging. Furthermore, there is the possibility that boronic acid membrane-based systems could be applied to pretreated biomass in future processing applications [7-9, 25]. These results demonstrate the potential of this approach to develop an IL pretreatment process technology with high overall sugar yields.

Acknowledgments We would like to thank Ozgul Persil Cetinkol and Andreia Michelle Smith for their contribution to the supplementary information. This work was part of the DOE Joint BioEnergy Institute (http://www.jbei.org) supported by the US Department of Energy, Office of Science, Office of Biological and Environmental Research, through contract DE-AC02-05CH11231 between Lawrence Berkeley National Laboratory and the US Department of Energy.

Open Access This article is distributed under the terms of the Creative Commons Attribution Noncommercial License which permits any noncommercial use, distribution, and reproduction in any medium, provided the original author(s) and source are credited.

\section{References}

1. Aziz H, Kamaruddin A, Bakar M (2008) Process optimization studies on solvent extraction with naphthalene-2-boronic acid ionpairing with trioctylmethylammonium chloride in sugar purification using design of experiments. Sep Purif Technol 60(2):190-197

2. Chandra RP, Bura R, Mabee WE, Berlin A, Pan X, Saddler JN (2007) Substrate pretreatment: the key to effective enzymatic hydrolysis of lignocellulosics? Adv Biochem Eng/Biotechnol 108:67-93

3. Conner J, Bulgrin V (1967) Equilibria between borate ion and some polyols in aqueous solution. J Inorg Nucl Chem 29(8):1953

4. Dadi AP, Varanasi S, Schall CA (2006) Enhancement of cellulose saccharification kinetics using an ionic liquid pretreatment step. Biotechnol Bioeng 95(5):904-910

5. Datta S, Holmes B, Park JI, Chen Z, Dibble DC, Hadi M et al. (2010) Ionic liquid tolerant hyperthermophilic cellulases for biomass pretreatment and hydrolysis. Green Chem 12:338-345

6. Demirbas A (2008) Biofuels sources, biofuel policy, biofuel economy and global biofuel projections. Energy Convers Manage 49(8):2106-2116

7. Di Luccio M, Smith B, Kida T, Borges C, Alves T (2000) Separation of fructose from a mixture of sugars using supported liquid membranes. J Membr Sci 174(2):217-224

8. Duggan P (2004) Fructose-permeable liquid membranes containing boronic acid carriers. Aust J Chem 57(4):291-299

9. Duggan PJ, Offermann DA (2009) Remarkably selective saccharide recognition by solid-supported peptide boronic acids. Tetrahedron 65(1):109-114

10. Earle M, Seddon K (2000) Ionic liquids. Green solvents for the future. Pure Appl Chem 72(7):1391-1398

11. Galbe M, Zacchi G (2007) Pretreatment of lignocellulosic materials for efficient bioethanol production. Adv Biochem Eng Biot 108:41-65 
12. Griffin GJ, Shu L (2004) Solvent extraction and purification of sugars from hemicellulose hydrolysates using boronic acid carriers. J Chem Technol Biotechnol 79(5):505-511

13. Himmel ME, Ding S-Y, Johnson DK, Adney WS, Nimlos MR, Brady JW et al. (2007) Biomass recalcitrance: engineering plants and enzymes for biofuels production. Science 315(5813):804807

14. Hu G, Heitmann JA, Rojas OJ (2008) Feedstock pretreatment strategies for producing ethanol from wood, bark, and forest residues. BioResources 3(1):270-294

15. Kamiya N, Matsushita Y, Hanaki M, Nakashima K, Narita M, Goto $M$ et al. (2008) Enzymatic in situ saccharification of cellulose in aqueous-ionic liquid media. Biotechnol Lett 30 (6): 1037-1040

16. Kilpelainen I, Xie H, King A, Granstrom M, Heikkinen S, Argyropoulos DS (2007) Dissolution of wood in ionic liquids. J Agric Food Chem 55(22):9142-9148

17. Li C, Knierim B, Manisseri C, Arora R, Scheller HV, Auer M et al. (2010) Comparison of dilute acid and ionic liquid pretreatment of switchgrass: biomass recalcitrance, delignification and enzymatic saccharification. Bioresour Technol 101:4900-4906

18. Li C, Wang Q, Zhao ZK (2008) Acid in ionic liquid: an efficient system for hydrolysis of lignocellulose. Green Chem 10(2):177182

19. Li C, Zhao ZK (2007) Efficient acid-catalyzed hydrolysis of cellulose in ionic liquid. Adv Synth Catal 349(11-12):1847-1850

20. Matsumoto M, Ueba K, Kondo K (2005) Separation of sugar by solvent extraction with phenylboronic acid and trioctylmethylammonium chloride. Sep Purif Technol 43(3):269-274

21. Mosier N (2005) Features of promising technologies for pretreatment of lignocellulosic biomass. Bioresour Technol 96(6):673-686

22. Pottkämper J, Barthen P, Ilmberger N, Schwaneberg U, Schenk A, Schulte $M$ et al. (2009) Applying metagenomics for the identification of bacterial cellulases that are stable in ionic liquids. Green Chem 11(7):957

23. Rinaldi R, Palkovits R, Schüth F (2008) Depolymerization of cellulose using solid catalysts in ionic liquids. Angew Chem Int Ed 47(42):8047-8050
24. Sienkiewicz PA, Roberts DC (1980) Chemical affinity systemsI: $\mathrm{pH}$ dependence of boronic acid-diol affinity in aqueous solution. J Inorg Nucl Chem 42(11):1559-1575

25. Smith B (1996) Liquid membrane transport using boronic acid carriers. Supramol Chem 7(1):55-60

26. Springsteen G, Wang B (2002) A detailed examination of boronic acid-diol complexation. Tetrahedron 58(26):5291-5300

27. Sun N, Rahman M, Qin Y, Maxim ML, Rodríguez H, Rogers RD (2009) Complete dissolution and partial delignification of wood in the ionic liquid 1-ethyl-3-methylimidazolium acetate. Green Chem 11(5):646

28. Swatloski R, Rogers R, Holbrey J (2004) Dissolution and processing of cellulose using ionic liquids. US Patent 6,824,599, 1 Jan 2004

29. Swatloski R, Spear S, Holbrey J, Rogers R (2002) Dissolution of cellose with ionic liquids. J Am Chem Soc 124(18):49744975

30. Takeuchi M, Koumoto K, Goto M, Shinkai S (1996) Efficient glucoside extraction mediated by a boronic acid with an intramolecular quaternary ammonium ion. Tetrahedron 52(40):12931-12940

31. Turner MB, Spear SK, Huddleston JG, Holbrey JD, Rogers RD (2003) Ionic liquid salt-induced inactivation and unfolding of cellulase from Trichoderma reesei. Green Chem 5(4):443

32. Van Duin M, Peters JA, Kieboom APG, Van Bekkum H (1985) Studies on borate esters. II: Structure and stability of borate esters of polyhydroxycarboxylates and related polyols in aqueous alkaline media as studied by ${ }^{11 \mathrm{~B}} \mathrm{NMR}$. Tetrahedron 41(16):3411-3421

33. Voget S, Steele HL, Streit WR (2006) Characterization of a metagenome-derived halotolerant cellulase. J Biotechnol 126 (1):26-36

34. Yang B, Wyman CE (2008) Pretreatment: the key to unlocking low-cost cellulosic ethanol. Biofuels Bioproducts and Biorefining 2(1):26-40

35. Zavrel M, Bross D, Funke M, Büchs J, Spiess AC (2009) Highthroughput screening for ionic liquids dissolving (ligno-)cellulose. Bioresour Technol 100(9):2580-2587

36. Zhao H, Baker GA, Song Z, Olubajo O, Crittle T, Peters D (2008) Designing enzyme-compatible ionic liquids that can dissolve carbohydrates. Green Chem 10(6):696-705 